\title{
LA TRANSFORMACIÓN DEL DERECHO DEPORTIVO POR INFLUENCIA DE LA UNIÓN EUROPEA
}

\author{
IÑAKI AgIRREAZKUEnaga \\ Catedrático de Derecho Administrativo \\ Universidad del País Vasco
}

\begin{abstract}
RESUMEN
¿Cuáles son las transformaciones más relevantes introducidas en el ordenamiento jurídico deportivo como consecuencia de la aplicación del derecho de la UE? Son múltiples los cambios introducidos en materia de libre circulación de deportistas profesionales, en el control de las ayudas de Estado y en la aplicación de las normas de competencia, formulando en ocasiones límites a la posición dominante de las federaciones deportivas.
\end{abstract}

Palabras clave: deporte; federación deportiva; Unión Europea; ayudas de Estado; normas de competencia.

\begin{abstract}
Which are the most remarkable transformations introduced in the sports legal order, as a result of applying European Union law? Many changes have been introduced in matters of free movement of professional sportspeople, concerning the control of state aids and the application of the competition rules, sometimes formulating limits to the dominant position of sports federations.
\end{abstract}

Key words: sport; sports federation; European Union; State aids; competition rules. 


\section{SUMARIO}

I.-INTROdUCCIÓN: DERECHO BLANDO (SOFT LAW) DE LA UE EN EL DEPORTE. II.-LA REVOLUCIÓN DEL CASO BOSMAN: LA LIBRE CIRCULACIÓN DE LOS DEPORTISTAS PROFESIONALES, CON EXTENSIÓN A LOS «COMUNITARIOS B». POSIBLE CUPO DE NACIONALES EN LOS EQUIPOS PROFESIONALES COMO MODO DE PRESERVAR LA CANTERA. III.-LAS MÚLTIPLES ESPECIFICIDADES DEL DEPORTE EN LA APLICACIÓN DEL DERECHO DE LA UE. IV.- REglas DE TRANSFERENCIA DE DEPORTISTAS PROFESIONALES. V.- ¿AYUUdAS DE Estado ilegales a Clubes de Fútbol españoles? NoRmas de COMPETENCia EN RELACIÓN CON LA POSICIÓN DOMINANTE DE LAS FEDERACIONES DEPORTIVAS, EL ANTIDOPAJE Y LA VENTA CONJUNTA DE DERECHOS AUDIOVISUALES DE COMPETICIONES DEPORTIVAS.

\section{INTRODUCCIÓN: DERECHO BLANDO (SOFT LAW) DE LA UE EN EL DEPORTE}

El derecho de la Unión Europea (UE) ha revolucionado el mundo del deporte profesional, y tiene una influencia no desdeñable, pero menor, y a veces imperceptible, en el mundo genérico del deporte amateur o en el denominado deporte para todos. Por lo tanto, el deporte como realidad económica, que es el que fundamentalmente trasciende a los medios de comunicación, se ha visto transformado por la aplicación del derecho de la UE, mientras que el deporte como realidad practicada por una gran parte de los ciudadanos europeos, tiene influencia del derecho de la UE con medidas suaves o blandas ( en desarrollo de los arts. 6 y 165 TFUE.

Recuérdese que solo tras la entrada en vigor del Tratado de Lisboa, en diciembre de 2009, la UE ostenta una competencia específica en materia de deporte. El art. 6 TFUE determina al deporte como ámbito en el que la UE tiene competencia para apoyar, coordinar o complementar la acción de los Estados, y el art. 165 TFUE dispone que la UE «contribuirá a fomentar los aspectos europeos del deporte, teniendo en cuenta sus características específicas, sus estructuras basadas en el voluntariado y su función social y educativa». La acción de la UE «se encaminará a desarrollar la dimensión europea del deporte, promoviendo la equidad y la apertura de las competiciones deportivas y la cooperación entre los organismos responsables del deporte, y protegiendo la integridad física y moral de los deportistas, especialmente de los más jóvenes». Todo ello en colaboración «con las organizaciones internacionales competentes en materia de educación y de deporte y, en particular, con el Consejo de Europa».

En desarrollo de esta nueva competencia en materia de deporte el Consejo de la UE, de 21 de mayo de 2014, ha aprobado su Plan de tra- 
bajo para el deporte (2014-2017) ${ }^{1}$, centrado en apoyar, coordinar y complementar la acción de los Estados, teniendo en cuenta la naturaleza específica del deporte, en particular en la lucha contra el dopaje, la lucha contra el amaño de los partidos, la protección de los menores, la financiación sostenible del deporte, el empleo y la formación en el deporte.

Con anterioridad, el 11 de julio de 2011, la Comisión aprobó su Comunicación sobre el «Desarrollo de la dimensión europea en el deporte» ${ }^{2}$. Pero en su documento de acompañamiento se confiesa que: «hasta ahora no se ha seguido ninguna estrategia para adoptar un enfoque de la UE sobre el deporte que comprometa a la Comisión y a los Estados miembros en torno a una agenda común y que permita afrontar los problemas de manera global. Tampoco se ha aprovechado plenamente el potencial del sector del deporte para contribuir a alcanzar los objetivos estratégicos de la UE en los ámbitos social y económico» ${ }^{3}$.

En la identificación de los problemas y los retos específicos de la UE en materia de deporte se centran — desde la aplicación del art. 165 TFUE - en la necesidad de tratar exclusivamente los problemas a escala de la UE bajo el principio de subsidiariedad: para desarrollar la función social y educativa del deporte (afrontando los problemas de salud por falta de actividad física; la exclusión social de los grupos desfavorecidos y el potencial del deporte para su integración; combinando el deporte y la educación); incrementar la sostenibilidad de las estructuras deportivas (con apoyo al voluntariado; con financiación sostenible del deporte, teniendo en cuenta los cambios normativos introducidos por los Estados miembros en el sector de los juegos de azar); afrontar la amenaza del dopaje para la integridad física y moral de los deportistas, la discriminación en el deporte por razón de la nacionalidad, explorar las posibilidades desaprovechadas para mejorar el diálogo sobre el deporte a escala de la UE, en resumen aclarar los ámbitos de aplicación del derecho de la UE al deporte. Y entre los objetivos específicos destacan los de promover la equidad y apertura en las competiciones deportivas; reforzar el diálogo y la cooperación con las partes interesadas del mundo del deporte; y mejorar la comprensión de la aplicación del derecho de la UE al deporte.

Obviamente la iniciativa de la UE en materia de deporte no sustituye a la acción de los Estados sino que pretende ser adicional, conforme

1 DOUE de 14 de junio de 2014, Resolución del Consejo y de los Representantes de los Gobiernos de los Estados miembros, reunidos en el seno del Consejo, de 21 de mayo de 2014, relativa al Plan de Trabajo de la Unión Europea para el Deporte (2014-2017) 2014/C 183/03. Tres años antes, el DOUE de 1 de junio de 2011 publicó la Resolución del Consejo relativa al Plan de Trabajo Europeo para el Deporte para 2011-2014.

$2 \operatorname{COM}(2011) 12$ final, de 18 de enero de 2011.

3 SEC(2011) 68 final. 
con el principio de subsidiariedad, allá donde los Estados no pueden responder de manera satisfactoria, en el marco de sus sistemas constitucionales. La iniciativa prevista no puede ir más allá de lo necesario para alcanzar sus objetivos, cumpliendo con los requisitos de proporcionalidad en el marco del mandato de los arts. 6 y 165 TFUE, que excluye la armonización y solo contempla la utilización de soft law o instrumentos suaves o blandos del derecho.

$\mathrm{Al}$ margen del soft law, ¿en qué ámbitos se ha producido una revolución o transformación del deporte por aplicación del derecho de la UE? En todos aquellos con relevancia económica, y de forma primordial destaca, en primer lugar, la abolición de las cláusulas de discriminación por razón de nacionalidad en las competiciones profesionales en el seno de la UE. Asimismo, por extensión es abolida también —la discriminación por razón de nacionalidad-para los llamados «comunitarios B», o deportistas con nacionalidad de países con Acuerdo de asociación con la UE. Acuerdos que a los deportistas habilitan a obtener licencia federativa en igualdad de condiciones de trabajo que al resto de deportistas con nacionalidad de países integrantes de la UE.

En segundo lugar, la especificidad del deporte también se reconoce en el seno de la UE (por ejemplo, con respeto a las reglas de juego, a la autonomía y diversidad de las organizaciones deportivas, a la estructura piramidal, a la organización del deporte sobre una base nacional, al principio de una única federación por deporte, etc.), pero nunca entendida tal especificidad como excepción a la aplicación del derecho de la UE en el deporte, del mismo modo que en el ordenamiento jurídico interno las especificidades del deporte no puede suponer una inaplicación del derecho público.

En tercer lugar, las reglas de transferencia de deportistas, con la determinación de quienes pueden tener la consideración como profesionales desde la aplicación del derecho de la UE, o la delimitación de los plazos de trasferencia para la preservación de la igualdad en las competiciones deportivas son cuestiones que inciden en la aplicación del derecho de la UE, con directa influencia en nuestro ordenamiento jurídico.

Por último, en cuarto lugar, la problemática planteada con eventuales ayudas de Estado para clubes españoles de fútbol, o la aplicación de las normas de competencia de la UE en relación, por ejemplo, con el antidopaje, la naturaleza de las federaciones deportivas como empresas con posición dominante en el mercado de las prestaciones de servicios de los agentes de los jugadores, o en el mercado de la venta de derechos de las retransmisiones deportivas, tiene una indudable influencia transformadora en nuestro ordenamiento jurídico. 
II. LA REVOLUCIÓN DEL CASO BOSMAN: LA LIBRE CIRCULACIÓN DE LOS DEPORTISTAS PROFESIONALES, CON EXTENSIÓN A LOS «COMUNITARIOS B». Posible CUPO DE NACIONALES EN LOS EQUIPOS PROFESIONALES COMO MODO DE PRESERVAR LA CANTERA

A) Libre circulación de los deportistas profesionales. Recuérdese que la STJ de 15 de diciembre de 1995, en el caso Bosman, declaraba que la libre circulación de trabajadores (art. 45 TFUE) se oponía a la aplicación de normas de asociaciones deportivas, que impedían hasta entonces a un jugador profesional de fútbol de un Estado miembro, al término de su contrato, ser fichado o empleado por otro club de otro Estado, salvo que se hubiese abonado al club de origen una compensación por transferencia, formación o promoción ${ }^{4}$.

Asimismo, la Sentencia declaraba que el art. 45 TFUE se oponía a la aplicación de normas adoptadas por asociaciones deportivas por las que en las competiciones por ellas organizadas, los clubes de fútbol sólo podían alinear un número limitado de jugadores profesionales nacionales de otros Estados miembros. La abolición de esta regla deportiva, por mor de la aplicación del derecho a la libre circulación de los deportistas profesionales nacionales de la Unión Europea, supuso una verdadera revolución en la medida que se fracturaba la hasta entonces regla limitativa que asociaba a los comunitarios con los extranjeros. A partir de la Sentencia Bosman todos los deportistas profesionales comunitarios pasaron a tener la consideración de nacionales a efectos deportivos, lo que revolucionó, internacionalizó y abarató muchas de las plantillas del deporte profesional en España.

Asimismo, en las conclusiones elaboradas por el abogado general Lenz en el caso Bosman (asunto C- 415/93), se llegaba a la conclusión de que el actual art. 101 TFUE debía interpretarse en el sentido de que se oponía a acuerdos entre clubes y decisiones entre federaciones deportivas que actuaban como empresas, y aplicaban reglamentos deportivos aprobados por las mismas federaciones justificando cláusulas de nacionalidad y normas de transferencia de futbolistas, limitativas en ambos casos de las normas de competencia comunitarias. La propia Comisión en sus observaciones escritas, en el caso Bosman, mantuvo la opinión

${ }^{4}$ Hay que recordar que para entonces en España ya estaba en vigor, desde hacía diez años, el Real Decreto 1006/1985 por el que se regula la relación especial de trabajo del deportista profesional. Con anterioridad en España se practicaba legalmente el derecho de retención, en virtud del cual el club en el que se había formado un futbolista tenía derecho a retenerlo, aun sin contrato, impidiendo que fichase por terceros. Este derecho de retención es el que todavía se aplicaba a Bosman en la década de los noventa en Bélgica, y que fue totalmente abolido por el Tribunal de Justicia. 
de que en relación con las normas sobre transferencias, sólo debían aplicarse las normas de competencia del Tratado.

En resumen, como consecuencia de la Sentencia Bosman, a partir de 1995, las cláusulas de nacionalidad y las normas sobre transferencias enjuiciadas, establecidas por la UEFA, fueron eliminadas de todo el ordenamiento jurídico deportivo europeo, por ser contrarias al derecho de la UE.

B) Libre circulación de los deportistas profesionales «comunitarios $B »$. El segundo paso, tras la Sentencia Bosman, en la revolución del cambio con las cláusulas limitativas de nacionalidad en el deporte profesional, llegó a España en el año 2000, con el caso Mills ${ }^{5}$. La cuestión controvertida se ceñía a determinar si Mills tenía derecho a ser reconocido como comunitario, a los efectos de obtener licencia e inscripción en la ACB, por su situación asimilada a la de los jugadores comunitarios en aplicación del Tratado suscrito entre Turquía y la CEE o, por el contrario, al no ser Turquía un Estado miembro de la Unión Europea no debía reconocérsele tal condición como argumentaba la ACB. La Sentencia firme de 14 de julio de 2000, del Juzgado de lo social $n^{\circ} 12$ de Barcelona, declara que el Tratado - entre Turquía y la CEE_ determina que «cada Estado miembro concederá a los trabajadores de nacionalidad turca empleados en la Comunidad un régimen caracterizado por la ausencia de toda discriminación por razón de nacionalidad con respecto a los trabajadores nacionales de los Estados miembros en lo que se refiere a condiciones de trabajo y remuneración». Por lo tanto, concluye la Sentencia que debe proscribirse «toda discriminación basada en la nacionalidad relativa a las condiciones de trabajo respecto a los restantes trabajadores españoles y/o comunitarios... por cuanto que es indudable que la posibilidad del deportista profesional de jugar en un equipo determinado forma parte de las condiciones de trabajo y, en consecuencia, la negativa a emitir una licencia como jugador nacional vulnera el principio de no discriminación por razón de la nacionalidad». Por todo ello, se estima la demanda y se declaran nulas las Resoluciones de la ACB, que no permitían a Mills prestar sus servicios como jugador profesional de baloncesto en igualdad de condiciones con los jugadores españoles y resto de comunitarios.

El Tribunal de Justicia llega a la misma conclusión en su Sentencia de 8 de mayo de 2003, en el caso Kolpak ${ }^{6}$. Sin embargo, el CSD inter-

\footnotetext{
5 Véase I. AgIrreazkuenaga (2000), «Crónicas de jurisprudencia. XV. Educación, Sanidad y Bienestar Social», Revista Justicia Administrativa, 9, págs. 228-229.

6 Kolpak era un jugador eslovaco de balonmano, a quien la Federación alemana sólo le tra-
} 
pretó que no era de aplicación tal jurisprudencia en España ${ }^{7}$, aunque con posterioridad la STJ de 12 de abril de 2005, C-265/03, en el caso del jugador ruso del Tenerife Simutenkov, reiteró la misma doctrina de aplicación también en España ${ }^{8}$.

El empecinamiento en esta materia del CSD y de la RFEF ha llevado a prolongar los casos durante casi una década, con multitud de procesos judiciales ${ }^{9}$, todos ellos resueltos de igual modo, en los que incluso se ha debido hacer frente al pago de responsabilidad patrimonial por los daños efectivamente causados ${ }^{10}$.

C) Cupo de nacionales en los equipos profesionales como modo de preservar la cantera. En el Libro Blanco sobre el Deporte, presentado por la Comisión el 11 de julio de $2007^{11}$, se señala que: «Las normas que obligan a los equipos a incluir un cupo determinado de jugadores formados a nivel local podrían considerarse compatibles con las disposiciones del Tratado sobre la libre circulación de personas si no dieran lugar a ningún tipo de discriminación directa por motivos de nacionalidad y si las posibles consecuencias indirectas de discriminación resultantes pu-

mitaba la licencia deportiva como extranjero. El Tribunal de Justicia concluye que el Acuerdo de Asociación entre la República Eslovaca y las Comunidades Europeas debía interpretarse en el sentido de que se opone a la aplicación a un deportista profesional de su nacionalidad, contratado de manera regular por un club establecido en un Estado miembro, «una norma adoptada por una federación deportiva del mismo Estado en virtud de la cual los clubes sólo están autorizados a alinear en los partidos de Liga y de Copa un número limitado de jugadores procedentes de países terceros que no formen parte del Acuerdo sobre el Espacio Económico Europeo». Lo que en otras palabras significa que los deportistas profesionales «Comunitarios B», desde el momento que estén legalmente contratados por un club como profesionales o trabajadores, tendrán derecho a obtener una licencia deportiva en igualdad de condiciones de trabajo que los comunitarios, de tal suerte que se proscriben para ellos las licencias deportivas de extranjero.

7 Véase el comunicado del CDS en I. AgIRREAzKuenaga (2003), «Derecho Comunitario y Deporte», Revista de Administración Pública, 161, págs. 300-301.

8 Simutenkov presentó a través de su club Tenerife, una solicitud a la RFEF para que sustituyese su licencia federativa como extranjero por una idéntica a la de los jugadores comunitarios. En apoyo de su solicitud invocaba el Acuerdo de colaboración entre las Comunidades y Rusia. Mediante Resolución de 19 de enero de 2001, la RFEF desestimó esta solicitud conforme a su Reglamento general y al Acuerdo celebrado el 28 de mayo de 1999 con la Liga Nacional de Fútbol Profesional. Y la cuestión prejudicial planteada por la Audiencia Nacional ante el Tribunal de Justicia fue la siguiente: «El artículo 23 del Acuerdo de colaboración [entre las Comunidades y Rusia], ¿se opone a que una federación deportiva aplique a un deportista profesional de nacionalidad rusa, contratado regularmente por un club de fútbol español, como el del recurso principal, una normativa en virtud de la cual los clubes sólo pueden utilizar en las competiciones de ámbito estatal un número limitado de jugadores procedentes de Estados terceros no pertenecientes al Espacio Económico Europeo?».

9 STS 24 de marzo 2006, Ar. 3717; STS 23 noviembre 2007, Ar. 826/2008. Auto Tribunal de Justicia, C-152/08, caso Nihat Kahveci...

10 Véase por ejemplo la Sentencia de la Audiencia Nacional de 26 de abril de 2012 (RJCA $2012 \backslash 288$ ) por la que se condena al pago de $180.303,64$ euros, más intereses, por la denegación de la licencia como comunitario a un jugador de la Real Sociedad de Futbol SAD.

11 COM (2007) 391 final, punto 2.3.9, pág. 6. 
dieran justificarse por ser proporcionadas a un objetivo legítimo perseguido, como mejorar y proteger la formación y el desarrollo de jóvenes deportistas con talento.»

Es lo que sucede en España en la ACB, que obliga a contar con jugadores en formación, jugadores de baloncesto «que entre su segundo año de categoría infantil y su segundo año de categoría senior, ambos inclusive, independientemente de su nacionalidad y edad hayan estado inscritos con cualquier club afiliado a la FEB en un período continuado o no de tres temporadas». El Convenio de 19 de julio de 2011 suscrito entre la FEB, la ACB y la ABP establece en cinco el número de licencias federativas correspondientes a los jugadores de formación, en plantillas de 12 jugadores, cifra que ha sido reducida a cuatro, tras requerimiento y dictamen motivado de la Comisión de la UE, por Resolución de 16 de julio de 2014 del $\mathrm{CSD}^{12}$, por la que se fijan nuevos cupos de jugadores de formación en las plantillas deportivas que participan en las competiciones oficiales de ámbito estatal de baloncesto ${ }^{13}$.

Sin embargo, la propia ACB ha recurrido contra la normativa que le es de aplicación, por entender que su propio Convenio es contrario al derecho de la UE, en la medida que les obliga a contar con jugadores en formación. La ACB sostiene, en esencia, en su recurso que teniendo en cuenta la peculiaridad de los jugadores de baloncesto cuyas condiciones físicas son determinantes para ser fichados por los clubes, así como que la mayoría de los clubes de la ACB cuenta en plantilla, respecto de las edades comprendidas en el acuerdo, en su mayoría con jugadores españoles, entienden que se produce una situación de discriminación contraria a los arts. 18 y 45 del TFUE, lo que afecta especialmente a los jugadores de formación tardía.

La Sentencia de la Audiencia Nacional, de 15 de junio de $2015^{14}$, sin juzgar que sea necesario plantear la cuestión de prejudicialidad solicita-

12 El BOE de 17 de julio de 2014 publica la Resolución, en cuyo preámbulo se explican los requerimientos de la Comisión y su posterior Dictamen motivado, de 16 de abril de 2014, en el que la norma sobre jugadores de formación en el baloncesto español no parece ser manifiestamente inadecuada aunque concluye que el establecimiento de cupos de jugadores de formación aprobado por acuerdo de fecha 19 de julio de 2011 es desproporcionado para alcanzar los objetivos perseguidos y dictamina que España ha incumplido las obligaciones que le incumben con arreglo al art. 45 TFUE, los artículos 1 y 4 del Reglamento (UE) n. ${ }^{\circ}$ 492/2011 y las disposiciones pertinentes de los acuerdos internacionales celebrados entre la Unión Europea y terceros países que incluyen una cláusula sobre igualdad de trato a los trabajadores, e invita a España a que adopte las medidas requeridas para ajustarse al dictamen motivado.

13 La Resolución de 16 de julio señala que «el CSD es plenamente competente para fijar los criterios sobre tramitación de licencias de jugadores de formación con el fin de garantizar los compromisos internacionales suscritos que, en el presente caso, resultan del dictamen motivado de la Comisión Europea de 16-4-2014 (infracción número 2010/2142), en el que se conmina a España a que ajuste la normativa sobre cupos de jugadores de formación a la normativa comunitaria».

14 Rec. 15/2015, JUR\2015\183967. 
da ante el TJ, entiende que la medida administrativa adoptada se justifica por la "finalidad legítima de proteger las "canteras de los clubs", y los gastos e inversiones de estos últimos en la formación de dichos jugadores así como en la potenciación de las selecciones nacionales», por lo que se desestima el recurso, y se acepta la compatibilidad con el derecho de la UE establecer cupos para jugadores en formación, de forma proporcionada, y sin que se incurra en discriminación directa por motivos de nacionalidad.

III. LAS MÚltiples ESPECIFICIDADES DEL DEPORTE EN LA APLICACión DEL DERECHO DE LA UE

La aplicación del derecho de la UE no es objeto de discusión en el ámbito del deporte. Sin embargo, durante años, como consecuencia de la Sentencia Bosman, por iniciativa de distintas federaciones deportivas internacionales — con algún apoyo de Estados miembros — se maniobró para que se reconociese lo que se denominaba «excepción deportiva», a introducir en la legislación de la UE. Por ejemplo, desde la Comisión en el XI Foro Europeo el Deporte ${ }^{15}$, en el documento de trabajo sobre «la toma en consideración del deporte en las políticas y acciones comunitarias», se señalaba que: «está claro que son las organizaciones deportivas las responsables de organizar y promover su disciplina, y, por lo tanto, las que deben establecer los reglamentos específicamente deportivos que vayan a aplicarse aunque, evidentemente, las legislaciones nacional y comunitaria tengan que respetarse».

Por consiguiente, las organizaciones deportivas deben adaptarse al derecho de la UE, o al derecho de los Estados, estando obligadas a introducir modificaciones en sus reglamentos, reforzando así la seguridad jurídica del deporte, aunque al mismo tiempo se reconoce la especificidad o autonomía del deporte, que siempre se extiende por lo menos a las reglas de juego o a los reglamentos puramente deportivos, es decir, a

15 Celebrado el 7 y 8 de noviembre de 2002. Entre las cuestiones que se someten a la reflexión de los participantes en el XI Foro Europeo del Deporte, destacan las siguientes: «¿Está el deporte suficientemente integrado en los diferentes programas o políticas comunitarios? $¿$ ¿Resulta satisfactorio para el mundo del deporte el enfoque transversal que se aplica actualmente? ¿Cómo podría el deporte sacar más fruto de determinados programas o iniciativas comunitarios? ¿Utiliza el mundo del deporte de la mejor forma posible el marco actual? En el Consejo de Niza de diciembre de 2000 se subrayó con especial énfasis la especificidad del deporte. ¿Se tiene suficientemente en cuenta esta especificidad en la actualidad? ¿Puede el deporte ser un medio para acercar la Unión Europea a sus ciudadanos? ¿Puede pasar la conciencia de ciudadanía europea por el deporte? ¿Deben las instancias europeas consultar con mayor frecuencia o de forma diferente a las organizaciones deportivas y, en particular, a las federaciones europeas? ¿Cuál es el futuro del deporte en el proceso de integración europea?». 
aquellos que ordenan la conducta de acción u omisión de los deportistas en las actividades que desarrollen en cada modalidad deportiva, y que por lo tanto su contenido — en principio — es irrelevante para el derecho público.

Ahora bien, lo que no cabe es enmascarar bajo la veste de las reglas de juego la nacionalidad de los jugadores alineables como pretendía la UEFA en el caso Bosman. Dado que como regla de juego puede incluirse el número de jugadores alineables en fútbol, pero nunca en el deporte profesional su nacionalidad, porque precisamente en este ámbito rige una norma jurídica de la UE que impide disponer inter-privatos de un principio básico como es la libertad de circulación de los trabajadores.

Como señala la Comisión —en su Libro Blanco del Deporte ${ }^{16}$ _, la especificidad del deporte europeo puede abordarse desde dos perspectivas: la primera, la relativa a la particularidad de las actividades deportivas y las normas en materia de deporte, como las competiciones separadas para hombres y mujeres, los límites en el número de participantes en las competiciones o la necesidad de garantizar la incertidumbre de los resultados y preservar el equilibrio competitivo entre los clubes que participan en las distintas competiciones. La segunda, la relativa a la particularidad de la estructura del deporte, que incluye, entre otras cosas, la autonomía y diversidad de las organizaciones deportivas; una estructura piramidal de las competiciones, desde la base hasta la elite, con mecanismos de solidaridad entre los diferentes niveles; organización de las federaciones deportivas sobre una base estatal; y una única federación por deporte y país.

Asimismo, como recuerda la Comunicación de la Comisión de 18 de enero de $2011^{17}$, el art. 165 TFUE reconoce al deporte como actividad especial, sometida al derecho de la UE (derechos fundamentales, libre circulación, prohibición de la discriminación, competencia, etc.). Por lo tanto, la especificidad del deporte exige evaluar la compatibilidad de las normas deportivas con el derecho de la UE, es decir que debe preservarse en el marco de la UE, por ejemplo, la equidad de las competiciones deportivas, la incertidumbre de los resultados, la protección de la salud de los deportistas, la promoción de la contratación y formación de jóvenes deportistas, la estabilidad financiera de los clubes deportivos o el ejercicio uniforme y coherente de un deporte con sus «reglas del juego».

No obstante, las cuestiones pueden complicarse a la vista de situaciones concretas a la hora de distinguir las reglas de juego o reglamentaciones específicas del deporte. Dos ejemplos bastan para el primero

16 COM (2007) 391 final, punto 4.2, pág. 12.

17 COM (2011) 12 final, pág. 12. 
relativo a una Decisión de la Comisión, no recurrida, de 9 de diciembre de 1999 (asunto Mouscron ${ }^{18}$ ), por la que se desestimaba una denuncia de Lille contra el acuerdo de UEFA por el que se impide al equipo belga de Mouscron jugar un partido de Copa de UEFA en la cercana ciudad francesa de Lille. Al efecto, la Comisión estimó que la norma de la UEFA, por la que cada club debe jugar su partido de casa en su propio campo es una regla de juego que no entra en el ámbito de aplicación de las normas de competencia del Tratado. Así, de forma harto discutible la Comisión considera como regla de juego inherente a las competiciones europeas de fútbol —en el ámbito de las relaciones transfronterizas entre países de la UE- la existencia de fronteras nacionales en el ámbito deportivo. ¿La respuesta de la UEFA hubiese sido similar si el partido se hubiese querido jugar en una ciudad igualmente próxima de Mouscron en Bélgica? Obviamente no, puesto que la UEFA declara que se debe jugar en el propio estadio del equipo o en un estadio del mismo país ${ }^{19}$. Por lo que si Lille estuviese en Bélgica —en lugar de en Francia- la UEFA hubiese admitido el cambio de estadio, y la Comisión no debiera haberse pronunciado sobre la naturaleza de tal decisión como regla de juego.

El segundo ejemplo de reglamentación puramente deportiva harto discutible lo proporciona el Tribunal de Primera Instancia en su Sentencia de 30 de septiembre de $2004^{20}$, al señalar que la lucha contra el dopaje no persigue objetivo económico alguno. Y se añade que «el acto deportivo es, esencialmente, un acto gratuito, sin carácter económico aun cuando el atleta lo realice como una actividad deportiva profesional. En otras palabras, la prohibición del dopaje y la normativa antidopaje se refieren exclusivamente a la faceta del acto deportivo que no tiene carácter económico, aun cuando sea un profesional quien realice dicho acto, lo que constituye su verdadera esencia». Por consiguiente se concluye que la prohibición del dopaje se basa en consideraciones puramente deportivas y es ajena a cualquier consideración económica, lo que significa que las normas de la lucha contra el dopaje no están comprendidas en el ámbito de aplicación de las disposiciones del Tratado de la UE. Como se verá (infra V), esta Sentencia ha sido anulada tras el posterior recurso de casación ante el

18 Denuncia de Lille contra la UEFA, IP/99/965 de 9 de diciembre de 1999. La cuestión debatida reviste clara vertiente económica porque el estadio de Mouscron tenía escasa capacidad para acoger a todos los que querían ver el partido de competición europea, mientras que el de Lille, cercano en kilómetros, pero situado en Francia, tenía capacidad suficiente.

19 Lo que reafirma J. F. Pons, a la sazón director general adjunto de la Dirección General de Competencia, en su artículo «Sport et Politique Europeenne de la Concurrente: Regles de Jeu et exemples recents d'application», Bruselas, 18 de octubre de 2001.

$20 \mathrm{~T}-313 / 02$, por la que desestima el recurso interpuesto contra la Decisión de 1 de agosto de 2002 de la Comisión, que a su vez desestimaba la denuncia presentada contra la normativa antidopaje de la Federación Internacional de Natación. 
Tribunal de Justicia ${ }^{21}$. Sin embargo, es ilustrativa del grado de confusión existente sobre la extensión de las normas de juego y reglamentaciones puramente deportivas, frente a la aplicación de los Tratados de la UE, o la normativa pública de los distintos Estados miembros ${ }^{22}$.

\section{REGLAS DE TRANSFERENCIA DE DEPORTISTAS PROFESIONALES}

A) Normativa sobre traspaso de futbolistas. Tras la Sentencia Bosman, en respuesta a varias denuncias presentadas ante la Comisión, se abrió una investigación pormenorizada de las normas de la FIFA sobre transferencias internacionales de futbolistas. Tanto la FIFA como la UEFA buscaban una escapatoria a la Sentencia Bosman, intentando formalizar largos contratos - de hasta quince años- a jóvenes futbolistas con extraordinaria proyección, con lo cual se aseguraban un nuevo modelo de derecho de retención. Y ni la FIFA ni la UEFA se encontraban completamente aisladas en defensa de sus postulados, ya que declaraciones públicas de significativos miembros del Consejo Europeo les daban cierto respaldo explícito ${ }^{23}$.

En tal contexto, se sitúa el Consejo Europeo de Niza de diciembre de 2000, en el que se aprobó una Declaración como Anexo IV, bajo el título de «las características específicas del deporte y su función social en Europa, que deben tenerse en cuenta al aplicar las políticas comunes». Es por ello que los responsables de la Comisión dan probadas muestras de intentar conciliar el derecho de la UE con la normativa propia de las federaciones deportivas, aunque esta última no se ciña a las reglas de juego y de competición.

Desde ese intento de conciliación, y desde la necesidad de hacer respetar la Sentencia Bosman, puede fácilmente entenderse la reunión celebrada el 5 de marzo de 2001, entre los comisarios Monti, Reding y Diamantopoulou, con los presidentes de la FIFA y UEFA, para alcanzar las bases de un acuerdo sobre traspasos internacionales de jugadores de fútbol. La FIFA y la UEFA se comprometieron a adoptar nuevas reglas de traspasos sobre la base de una serie de principios ${ }^{24}$, destinados a fo-

21 Por la Sentencia de 18 de julio de 2006, C-519/04, caso David Meca Medina.

$22 \mathrm{Al}$ efecto pueden verse las reflexiones sobre los casos Contador o Heras en T. R. FERnáNDEz (2015), La justicia deportiva. Cuatro estudios, Madrid: Civitas, págs. 102 y ss.

23 Es preciso recordar que tanto el primer ministro británico Tony Blair como el a la sazón canciller alemán Gerard Schroeder y el presidente francés Jacques Chirac se manifestaron públicamente contra la reforma del sistema de traspasos de los futbolistas, reconociendo que el sistema vigente no era perfecto, pero temiendo que una reforma pudiese tener un impacto negativo en las estructuras del fútbol europeo. Véase El País de 10 de septiembre de 2000.

24 Comunicado de la Comisión IP/01/314 de 6.3.2001. Los cinco principios sobre los que 
mentar la formación de los jugadores jóvenes, a garantizar la estabilidad de los equipos, la integridad, la regularidad y el correcto funcionamiento de las competiciones, en el contexto de las especificidades del mercado del fútbol. Así, se alcanza un acuerdo sobre las indemnizaciones en concepto de formación. La Comisión considera legítimo que el club que lo ha formado quiera percibir una indemnización por el coste de la formación que le ha proporcionado ${ }^{25}$. Respecto a la duración de los contratos se limita su duración máxima a cinco años, y la mínima a un año. Y para resolver los conflictos se prevén órganos de arbitraje paritarios, compuestos por representantes de jugadores y clubes, con una instancia de apelación, sin que se prive a los jugadores de su derecho a la tutela judicial, si así lo desean, acudiendo a los tribunales ordinarios ${ }^{26}$.

Por supuesto, toda esta normativa privada pactada entre la FIFA, la UEFA y la Comisión es de aplicación supletoria en España, donde rige el ya mencionado Real Decreto 1006/1985. Ahora bien, en lo que concierne a la transferencia internacional de jugadores menores de 18 años, el art. 19.1 del Reglamento de la FIFA directamente lo prohíbe, y solo se pue-

se consigue un inicial acuerdo son los siguientes: 1. Se establecen dos periodos fijos para los traspasos al año: mercado de invierno y mercado de verano. 2. La duración de los contratos será de un mínimo de un año y de un máximo de cinco. 3. Se creará un mecanismo de solidaridad entre clubes. 4. Se constituirá un cuerpo de arbitraje «objetivo» y «efectivo», sin excluir el recurso ante los tribunales nacionales. 5. Se establece un principio de compensación por los costes de formación de los jóvenes.

${ }_{25}$ Evidentemente, el problema radica en calcular ese coste real de formación. Al efecto, la STJ de 16 de marzo de 2010, C-325/08, tiene por objeto una petición de decisión prejudicial planteada, con arreglo al artículo $234 \mathrm{CE}$, por la Cour de cassation (Francia), presentada en el marco de un litigio entre el club «Olympique Lyonnais» y el Sr. Bernard, jugador de fútbol profesional, así como el Newcastle, club inglés, respecto al pago por estos últimos de una indemnización a causa de la infracción unilateral por el Sr. Bernard de sus compromisos derivados del artículo 23 de la Charte du football professionnel para la temporada 1997-1998 de la Fédération Française de Football. El tribunal remitente pregunta, en resumen, si un régimen conforme al que un jugador "promesa» se expone a una condena al pago de una indemnización cuando al término de su período de formación no firma un contrato como jugador profesional con el club que le ha formado, sino con un club de otro Estado miembro, constituye una restricción en el sentido del artículo 45 TFUE, y en su caso si ésta se justifica por la necesidad de fomentar la contratación y la formación de jóvenes jugadores. El Tribunal de Justicia responde que el artículo 45 TFUE no se opone a un sistema que, para realizar el objetivo consistente en fomentar la contratación y la formación de los jóvenes jugadores, garantiza la indemnización del club formador en el caso de que un joven jugador firme al término de su período de formación un contrato como jugador profesional con un club de otro Estado miembro, siempre que ese sistema sea apto para garantizar la realización de ese objetivo y no vaya más allá de lo necesario para lograrlo. Pero para garantizar tal objetivo no cabe establecer un régimen que exponga al jugador promesa a la condena al pago de una indemnización cuyo importe no guarda relación con los costes reales de formación.

26 Lógicamente, tras la entrada en vigor de las nuevas normas se retiraron las denuncias presentadas ante la Comisión. Posteriormente, la Comisión, el 5 de junio de 2002, archivó el procedimiento incoado al desestimar oficialmente otras dos denuncias. Éstas se centraban en la prohibición de que los jugadores rescindieran unilateralmente su contrato, problema que se resuelve con el nuevo Reglamento sobre el Estatuto y Transferencia de jugadores de la FIFA. Comisión IP/02/824. 
de obtener el correspondiente certificado de transferencia internacional (CTI), en el caso de jugadores menores de 18 años: «Si los padres del jugador cambian su domicilio al país donde el nuevo club tiene su sede por razones no relacionadas con el fútbol. O si la transferencia se efectúa dentro del territorio de la Unión Europea (UE) o del Espacio Económico Europeo (EEE) y el jugador tiene entre 16 y 18 años de edad... ${ }^{27}$.

Precisamente por llevar a cabo fichajes irregulares de menores infringiendo el art. 19 ha sido sancionado por la FIFA el Barcelona, como se sabe, con la prohibición de fichar durante dos periodos de contratación en todas las categorías (hasta enero de 2016), además de a una multa de 370.000 euros, todo ello confirmado por el TAS. Igualmente, por similares hechos parece que la FIFA investiga al Real Madrid, y a otras SAD españolas como Atlético de Madrid, Villarreal, Rayo Vallecano o Valencia ${ }^{28}$. El problema reside en que las respectivas escuelas o academias de fútbol organizadas por estos equipos incorporan a menores de edad extranjeros, como si sus padres cambiasen de domicilio, pero el Reglamento exige que el cambio de domicilio no sea por motivos relacionados con el fútbol.

B) Plazos de transferencia e inscripción. Existe unanimidad al considerar que los plazos de transferencia de los jugadores representan un obstáculo a la libre circulación de los deportistas profesionales en la UE, pero se justifica en principio por la peculiaridad del mercado propio por el que se regulan las distintas competiciones deportivas, aunque la variabilidad entre los plazos establecidos, y la gama abierta de supuestos que se plantean en las distintas competiciones, exige analizar los diferentes casos de forma singularizada.

Así, cuando el Tribunal de Justicia se ha enfrentado al litigio concreto de determinar si los plazos para la transferencia de los jugadores se justifican por motivos no económicos, que sólo conciernen a la regularidad de la competición deportiva, tras la cuestión prejudicial planteada, ha decidido que corresponde al órgano jurisdiccional nacional comprobar en qué medida tal diferencia de trato se justifica por razones objetivas que se refieren únicamente al deporte como tal, o que obedezcan a diferencias existentes entre la situación de los jugadores

27 También si: «El jugador vive en su hogar a una distancia menor de $50 \mathrm{~km}$ de la frontera nacional, y el club de la asociación vecina está también a una distancia menor de $50 \mathrm{~km}$ de la misma frontera en el país vecino. La distancia máxima entre el domicilio del jugador y el del club será de $100 \mathrm{~km}$. En tal caso, el jugador deberá seguir viviendo en su hogar y las dos asociaciones en cuestión deberán otorgar su consentimiento».

28 Al respecto véase A. Palomar (coord.) (2015), Los menores en la actividad futbolística: marco jurídico y reflexiones de contexto, Pamplona: Thomson Reuters Aranzadi. 
procedentes de una federación europea o no europea ${ }^{29}$, porque si la competición deportiva no justificase los plazos concretos establecidos, se vulneraría el derecho a la libre circulación de los deportistas profesionales en la UE.

C) Deportistas profesionales para el derecho de la UE. ¿Cuándo y por quién debe ser clasificado un deportista como profesional o amateur? En España, el Real Decreto 1006/1985, establece que: «Son deportistas profesionales, quienes, en virtud de una relación establecida con carácter regular, se dediquen voluntariamente a la práctica del deporte por cuenta y dentro del ámbito de organización y dirección de un club o entidad deportiva a cambio de una retribución» (art. 1.2). Por lo tanto, todos los deportistas, aunque estén contratados como aficionados, que reciban un sueldo de un club o una federación por cuya cuenta ejercen una actividad deportiva, estando sometidos a su dirección y disciplina, deben tener la consideración de profesionales. Si bien un caso intermedio lo representan todos aquellos deportistas que, a cambio de una beca o premios recibidos en competición, llevan a cabo una actividad deportiva de forma semiprofesional.

Precisamente, respecto a estos últimos se pronuncia el Tribunal de Justicia $^{30}$, desde la libre prestación de servicios, en relación con si deben estar en posesión de una autorización de su federación deportiva para poder tomar parte en una competición internacional en la que no se enfrenten equipos nacionales. En contra de las alegaciones presentadas por la Comisión, y los representantes de los Gobiernos de la UE que comparecen, el Tribunal admite pronunciarse sobre la cuestión planteada partiendo de la circunstancia de que la calificación de amateurs que pueda atribuir una asociación o federación a sus deportistas, no excluye que desempeñen actividades económicas, concretadas en primas, ayudas, premios o subvenciones en función de los resultados,

29 En el caso concreto de la STJ de 13 de abril de 2000, C-415/93, caso Lehtonen, en la normativa deportiva cuestionada se establece que las transferencias de los jugadores procedentes de una federación, que no pertenezca a la zona europea, la fecha límite será el 31 de marzo, y no la del 28 de febrero, que se aplica únicamente a los jugadores procedentes de una federación de la zona europea. El Tribunal considera que tal normativa parece ir más allá de lo que resulta necesario para alcanzar el objetivo perseguido, ya que de los elementos que obran en autos no se desprende que la transferencia realizada entre el 28 de febrero y el 31 de marzo de un jugador procedente de una federación de la zona europea presente más riesgos para la regularidad del campeonato que la transferencia, durante ese mismo período de tiempo, de un jugador procedente de una federación no europea. Para una comprensión más detallada de la materia véase I. AgIRREAzKuEnAGa (2000), «Función social y perspectiva económica del deporte en el marco comunitario. Especial referencia a los casos Lehtonen y Deliège», Revista de Administración Pública, 152, págs. 109-124.

30 STJ de 11 de abril de 2000, caso Deliège. 
o contratos de patrocinio, por lo que no pueda excluirse su vertiente semiprofesional.

Sin embargo, en cuanto a la cuestión de fondo, el Tribunal entiende que las normas de selección para participar en competiciones internacionales, y las correspondientes autorizaciones federativas inherentes a la organización de las competiciones, no constituyen, en sí mismas, una restricción a la libre prestación de servicios. Además, se indica que, a diferencia del caso Bosman, las normas de selección de deportistas —por las federaciones - no determinan sus condiciones de acceso al mercado de trabajo.

V. ¿Ayudas de Estado ilegales a clubes de fútbol españoles? Normas DE COMPETENCIA EN RELACIÓN CON LA POSICIÓN DOMINANTE DE LAS FEDERACIONES DEPORTIVAS, EL ANTIDOPAJE Y LA VENTA CONJUNTA DE DERECHOS AUDIOVISUALES DE COMPETICIONES DEPORTIVAS

A) ¿Ayudas de estado ilegales a clubes de futbol españoles? El Diario Oficial de la UE de 7 de marzo de 2014 da publicidad a tres expedientes investigados por la Comisión en relación con presuntas ayudas de Estado a clubes de fútbol españoles ${ }^{31}$. En primer lugar, se investiga al Real Madrid porque el Ayuntamiento de Madrid ha podido concederle una ayuda ilegal mediante un convenio urbanístico suscrito el 29 de julio de 2011. Este convenio tiene por objeto, entre otras cosas, resolver una cuestión jurídica pendiente referida a una permuta de bienes inmuebles que fue objeto de varios convenios precedentes en 1996 y 1998. En resumen, la Comisión duda de que se haya determinado un valor de mercado de la parcela «Las Tablas». Entiende que ni en 1998 ni en 2011 se efectuó una tasación independiente. La Comisión también duda en cuanto a que sea conforme a mercado el valor de los terrenos que se entregaron al Real Madrid por el Convenio de 2011 y con motivo de la posterior permuta de terrenos en las inmediaciones del Estadio Bernabéu. La Decisión de la Comisión de 4 de julio de 2016 (SA. 33754) determina que el Real Madrid debe devolver 18,4 millones de euros al Ayuntamiento de Madrid.

En segundo lugar, la Comisión investiga ayudas del Instituto Valenciano de Finanzas al otorgar tres avales para préstamos bancarios por un total de 107 millones de euros a las fundaciones del club de fútbol Valencia, a la del Hércules y a la del Elche. En los tres casos la finali-

31 Véase R. Terol Gómez (2014), «Deporte y ayudas de Estado», Revista Española de Derecho Europeo, 52, págs. 49-87. 
dad de los préstamos era financiar la adquisición de acciones de sus respectivas SAD. En consecuencia la Comisión constata las ayudas de funcionamiento a los tres clubes Valencia CF, Hércules CF y Elche CF, que no pueden justificarse a tenor del art. 107. 3.c) TFUE. La Decisión de la Comisión de 4 de julio de 2016 (SA. 36387) obliga al Valencia a devolver 20,4 millones de euros, al Hércules 6,1 millones de euros y al Elche 6,7 millones de euros.

En tercer lugar, se abre expediente a los cuatro clubes que tras la aprobación de la Ley del Deporte de 1990 no estaban obligadas a transformarse en SAD (Real Madrid, Barcelona, Athletic de Bilbao y Osasuna), de conformidad con su disposición adicional $7^{\mathrm{a}}$, al tener un saldo patrimonial neto de carácter positivo desde la temporada 1985-1986. Como el trato fiscal a los clubes deportivos difiere del régimen fiscal aplicable a las sociedades anónimas deportivas, los clubes deportivos, calificados como entidades sin ánimo de lucro, pueden acogerse a una exención parcial del impuesto sobre sociedades con arreglo al art. 9.3.a) de la Ley del Impuesto sobre Sociedades, exención que les supone tributar al 25\% en lugar de al tipo general del 30\%. Por consiguiente, la Comisión considera que España otorga ayuda de funcionamiento mediante un tipo impositivo preferente a los cuatro clubes deportivos, lo que puede considerarse como ayuda ilegal, al no poder justificarse con arreglo al art. 107 TFUE. Ahora bien, parece que en este caso el problema discriminatorio puede ser de orden interno, más que del conjunto de la UE, donde el tipo impositivo de sociedades aplicable a los clubes de fútbol de la UE varía significativamente de país a país, a falta de cualquier tipo de armonización fiscal comunitaria. Sin embargo, la Decisión de la Comisión de 4 de julio de 2016 (SA. 29769) establece que cada club debe devolver entre 0 y 5 millones de euros según lo determinen las autoridades españolas en el proceso de recuperación.

Finalmente, el a la sazón vicepresidente de la Comisión, y comisario de competencia, Sr. Almunia, señalaba que también se ha examinado el asunto de las deudas que clubes españoles mantienen con el Estado, y que, según han denunciado otros clubes de fútbol europeos, podrían suponer ayudas públicas encubiertas ${ }^{32}$, aunque parece que no se ha llegado hasta el momento a conclusión alguna.

B) Posición dominante de federaciones deportivas. La Comisión consideró no conforme con la UE el Reglamento de la FIFA de agentes de jugadores. Ante su requerimiento, la FIFA decidió revisarlo y su nueva

32 Iusport.com de 18 de diciembre de 2013. 
redacción satisface a la Comisión al establecer pruebas objetivas y transparentes $^{33}$, y no reservar la profesión a quienes pudieran depositar en la FIFA una fianza de 200.000 francos suizos, sustituida por un seguro de responsabilidad civil ${ }^{34}$.

El Sr. Piau mantuvo su denuncia alegando que las infracciones persistían en el Reglamento modificado y que se habían introducido nuevas restricciones bajo la forma de normas deontológicas, de modelo de contrato y respecto a la determinación de la remuneración. Mediante Decisión de 15 de abril de 2002 la Comisión desestimó la denuncia del Sr. Piau, quien la recurre ante el Tribunal de Primera Instancia que - por Sentencia de 26 de enero de 2005- reconoce a la FIFA como una asociación de empresas en el sentido del artículo 101 TFUE, que desarrolla una actividad económica de prestación de servicios que no se encuadra dentro de la especificidad deportiva, tal como la define la jurispruden$\mathrm{cia}^{35}$. Y el reglamento de la FIFA acredita la voluntad de regular la actividad de los agentes de jugadores y, por tanto, constituye una decisión de una asociación de empresas en el sentido del art. 101.1 TFUE, sujeta a las normas comunitarias de competencia.

A juicio del TPI, es evidente que tal regulación corresponde al control de una actividad económica y afecta a libertades fundamentales. No obstante, la competencia normativa ejercida por la FIFA sólo puede examinarse en la medida en que afecte a las normas sobre la competencia, aunque el objeto de control jurisdiccional del Tribunal de Primera Instancia debe centrarse en el examen de la Decisión de la Comisión impugnada.

Al efecto, el Tribunal entiende que la Comisión no efectuó una apreciación manifiestamente errónea de las disposiciones del Reglamento

33 Téngase en cuenta que de conformidad con la información que se extrae del n 103 de la Sentencia del Tribunal de Primera Instancia de 26 de enero de 2005 (T-313/02, caso Piau), mientras que en 1996 se contabilizaban 214 agentes de jugadores de fútbol, se estimaba en 1.500 a principios del año 2003, y 300 candidatos habían aprobado el examen en las sesiones organizadas en marzo y septiembre de ese mismo año 2003. En 2011, en la UE hay en torno a 6.000 agentes deportivos, en más de 30 modalidades deportivas, de conformidad con los datos que se extraen de un estudio independiente de la Comisión, elaborado bajo del título Etude sur les agents sportifs dans l'union europeenne, noviembre de 2009.

34 De conformidad con la información que se desprende del documento de la Comisión IP/02/585, de 18 de abril de 2002, «todo candidato a la profesión de agente de jugadores deberá pasar un examen en forma de cuestionario con respuestas múltiples. Todo candidato que obtenga el número mínimo de puntos requeridos habrá superado el examen. Las fechas de examen y gran parte de las preguntas serán las mismas en todo el mundo. Para obtener la licencia, el candidato debe a continuación contratar un seguro de responsabilidad civil en el ejercicio de la profesión que sirve para cubrir eventuales demandas por daños y perjuicios de jugadores o clubes originadas por actividades contrarias a los principios del reglamento».

35 De acuerdo con la jurisprudencia derivada de las Sentencias del Tribunal de Justicia de 14 de julio de 1976, Donà, 13/76, Rec. p. 1333, apartados 14 y 15; de 15 de diciembre de 1995 , Bosman, C-415/93, Rec. p. I-4921, apartado 127; Deliège, apartados 64 y 69, y de 13 de abril de 2000, Lehtonen y Castors Braine, C-176/96, Rec. p. I-2681, apartados 53 a 60. 
modificado por la FIFA ${ }^{36}$. Sin embargo, la licencia, que impone la FIFA y que condiciona el ejercicio de la profesión de agente de jugadores, constituye una barrera al acceso a esta actividad económica y, por tanto, afecta necesariamente al juego de la competencia. Ahora bien, el sistema de licencias no elimina la competencia, porque dicho sistema supone una selección cualitativa, adecuada para satisfacer el objetivo de profesionalización de la actividad de agente de jugadores, más que una restricción cuantitativa del acceso de la profesión. En consecuencia, concluye que la Comisión no incurrió en un error manifiesto de apreciación al estimar que las restricciones derivadas de la obligatoriedad de la licencia podían acogerse a una exención en virtud del artículo 101.3 TFUE.

Desde la aplicación del art. 102 TFUE el Tribunal entiende que se trata de un mercado de prestación de servicios en el que los compradores son los jugadores y los clubes, y los vendedores son los agentes. En este mercado, puede considerarse que la FIFA actúa por cuenta de los clubes de fútbol, de los que emana en su condición de Federación. En tal mercado, una decisión como el Reglamento de la FIFA vincula a los clubes, en cuanto a su comportamiento, y debido a la obligatoriedad del Reglamento para las asociaciones nacionales miembros de la FIFA y los clubes integrados en aquéllas, se muestran vinculadas de forma duradera en cuanto a su comportamiento por normas que aceptan y que los

36 Añade además el Tribunal que «las disposiciones relativas al contenido del contrato entre el agente y el jugador según las cuales el contrato, escrito, debe precisar los criterios y formas de pago de la remuneración del agente y no puede tener una duración superior a dos años, aunque sea renovable, no revelan menoscabos de la competencia. La limitación de la duración de los contratos a dos años, que no impide la renovación del compromiso, resulta adecuada para propiciar la fluidez del mercado y, por tanto, de la competencia. Por el contrario, esta delimitación relativamente restringida de las relaciones contractuales parece apropiada para contribuir a asegurar las relaciones financieras y jurídicas de las partes sin poner en peligro, en cambio, la competencia» $\left(\mathrm{n}^{\circ} 93\right)$. Asimismo, "el régimen de sanciones... aunque pueda afectar a las normas sobre la competencia, no resulta criticable. Del Reglamento modificado se desprende que las sanciones aplicables a los agentes, a los jugadores y a los clubes son la amonestación, la censura, la advertencia, la suspensión o la retirada de la licencia para los agentes, la suspensión de doce meses como máximo para los jugadores y la suspensión o la prohibición de tres meses como mínimo para los clubes, lo cual no puede considerarse manifiestamente excesivo tratándose de un régimen de sanciones profesionales. Además, los importes de las multas previstas para los jugadores y los clubes se redujeron respecto a los que figuraban en el Reglamento inicial» ( $\left.n^{\circ} 94\right)$. Por último, «en lo que atañe a los medios de impugnación ante los tribunales de derecho común, y suponiendo que las disposiciones del Reglamento modificado puedan incidir a este respecto en las normas sobre la competencia, de las respuestas de la FIFA y de la Comisión a las preguntas del Tribunal de Primera Instancia antes mencionadas se desprende que, independientemente del sistema de recursos contra las decisiones de las asociaciones nacionales o de la Comisión del Estatuto del Jugador, competente para los agentes de jugadores, ante el Tribunal de Arbitraje Deportivo, los interesados pueden siempre dirigirse a los tribunales de derecho común, en particular para hacer valer los derechos que les confieren el derecho nacional o el derecho comunitario, teniendo en cuenta además que las decisiones del Tribunal de Arbitraje Deportivo pueden ser objeto de un recurso de anulación ante el Tribunal Federal suizo» ( $\mathrm{n}^{\circ}$ 95). 
demás actores (jugadores y agentes de jugadores) no pueden contrariar so pena de sanciones que, para los agentes de jugadores en particular, pueden llevar a excluirlos del mercado. Lo que evidencia una posición dominante colectiva de los clubes en el mercado de las prestaciones de servicios de los agentes de jugadores, puesto que los clubes, mediante la normativa a la que se adhieren, imponen las condiciones en las que se efectúan las prestaciones de servicios.

En tal contexto, resulta artificial sostener que la FIFA, cuyo poder de dirección de la actividad deportiva del fútbol y de las actividades económicas vinculadas - entre las que se hallaría la desarrollada por la actividad de los agentes de jugadores - no ostenta una posición dominante colectiva en el mercado de las prestaciones de servicios de los agentes de jugadores. Ahora bien, a juicio del Tribunal, una cosa es que la FIFA ostente una posición dominante en el mercado de prestación de servicios de los agentes de jugadores, y otra distinta es que concurra abuso de posición dominante, que no lo estima como acreditado, ya que el Reglamento no impone restricciones cuantitativas al acceso a la actividad de agente de jugadores que sean perjudiciales para la competencia, sino restricciones de carácter cualitativo que pueden estar justificadas. Por lo tanto, pese al error de derecho cometido por la Comisión al estimar que el artículo 102 TFUE no era aplicable, su aplicación no habría podido en ningún caso desembocar en la apreciación de un abuso de posición dominante.

C) ¿Restricción de la competencia por las normas antidopaje? En el caso David $\mathrm{Meca}^{37}$, la decisión de la Comisión recurrida no califica al COI como empresa. Sin embargo, el Tribunal de Justicia considera que la Comisión se puso, como resulta explícitamente del apartado 37 de la Decisión recurrida, en la situación de que el COI tuviese que ser calificado como empresa, en tanto que asociación de asociaciones internacionales y nacionales de empresas ${ }^{38}$. Respecto al contexto en el que se adoptó la normativa controvertida, la Comisión podía considerar con

37 Recuérdese que en primera instancia la STPI 30 de septiembre 2004, T-313/02, desestima el recurso interpuesto contra la Decisión de 1 de agosto de 2002 de la Comisión. Tras el posterior recurso de casación, la STJ de 18 de julio de 2006, C-519/04, anula la Sentencia recurrida, aunque desestima el recurso interpuesto ante el Tribunal de Primera Instancia.

38 Sin embargo, la compatibilidad de una normativa con el derecho comunitario de competencia no puede apreciarse de manera abstracta, porque no todo acuerdo entre empresas, ni toda decisión de una asociación de empresas, que restrinjan la libertad de acción de las partes o de una de ellas están comprendidos necesariamente en la prohibición del artículo 101.1 TFUE. Debe tenerse en cuenta el contexto global en que se adoptó la decisión de la asociación de empresas, y a continuación deberá examinarse si los efectos restrictivos de la competencia que resultan son inherentes a la consecución de dichos objetivos y proporcionados. 
razón que su objetivo era luchar contra el dopaje para que la competición deportiva se desarrolle con igualdad de oportunidades entre los atletas, preservando su salud, la integridad y objetividad de la competición, así como los valores éticos en el deporte.

Por otra parte, dado que las sanciones son necesarias para garantizar el cumplimiento de la prohibición de dopaje, el efecto de éstas en la libertad de acción de los atletas debe considerarse, en principio, inherente a las normas antidopaje. Así, aun suponiendo que la normativa deba ser apreciada como una decisión de una asociación de empresas que limita la libertad de acción de los recurrentes, no puede constituir forzosamente una restricción de la competencia incompatible con el mercado común, en el sentido del art. 101 TFUE, puesto que está justificada por un objetivo legítimo. Sin embargo, los recurrentes sostienen que la normativa antidopaje tiene también la finalidad de garantizar los intereses económicos propios del COI y que precisamente para preservar esta finalidad se adoptan normas excesivas, como las impugnadas, y en tal sentido no pueden considerarse, por tanto, inherentes al buen funcionamiento de la competición y eludir las prohibiciones del artículo 101 TFUE.

$\mathrm{Al}$ respecto, la Sentencia del TJ admite el carácter represivo de la normativa antidopaje y que las sanciones aplicables en caso de violarla pueden producir efectos negativos en la competencia, sobre todo si las sanciones fuesen infundadas, dada la exclusión de los deportistas de las competiciones. Por ello las sanciones deben limitarse a lo necesario para asegurar el buen funcionamiento de las competiciones deportivas. En el caso concreto examinado, el umbral de lo sancionable en la normativa se halla en $2 \mathrm{ng} / \mathrm{ml}$ de orina, a partir del cual la presencia de nandrolona en el cuerpo del atleta constituye dopaje. Los recurrentes impugnan esta norma alegando que ese límite máximo es demasiado bajo y que no se basa en ningún criterio de seguridad científico. No obstante, los recurrentes no demuestran que la Comisión haya incurrido en un error manifiesto de apreciación, ya que queda acreditado que la nandrolona es una sustancia anabolizante cuya presencia en el cuerpo de los atletas puede mejorar sus resultados y falsificar el resultado de la competición. El principio de prohibición que afecta a esta sustancia se justifica por el propio objeto de la normativa antidopaje ${ }^{39}$.

39 También queda acreditado que esa sustancia puede producirse de forma endógena y que, para tener en cuenta este fenómeno, las instancias deportivas, en particular el COI por medio de la normativa antidopaje, admiten que sólo se considere dopaje efectivo la presencia de dicha sustancia por encima de un determinado límite máximo. Por lo tanto, sólo en el supuesto de que, habida cuenta del estado de los conocimientos científicos en el momento de la adopción de la normativa antidopaje o incluso en el momento de su aplicación a los recurren- 
De los autos se desprende que la eventual producción endógena media observada en todos los estudios publicados era veinte veces inferior a 2 $\mathrm{ng} / \mathrm{ml}$ de orina y que el valor máximo de la producción endógena observado era inferior en cerca de un tercio. Si bien los recurrentes sostienen que, desde 1993, el COI no podía ignorar el riesgo señalado por un experto de que el simple consumo de una cantidad limitada de cerdo macho sin castrar podía llevar a que atletas totalmente inocentes superasen el límite máximo de que se trata, aunque no se ha acreditado que la mayoría de la comunidad científica hubiese confirmado ese riesgo ${ }^{40}$. En estas circunstancias, y puesto que los recurrentes no especifican en qué nivel debía haberse fijado el umbral de tolerancia, no se puede concluir que las restricciones impuestas por ese umbral a los deportistas profesionales vayan más allá de lo necesario para garantizar el desarrollo y buen funcionamiento de las competiciones deportivas. Además, concluye el Tribunal de Justicia que como los recurrentes no han invocado el carácter excesivo de las sanciones aplicables e impuestas, no queda demostrado, por lo tanto, el carácter desproporcionado de la normativa antidopaje.

D) Venta conjunta de derechos audiovisuales de competiciones deportivas. La Comunicación de la Comisión de 18 de enero de 2011, sobre «Desarrollo de la dimensión europea en el deporte» ${ }^{41}$, señala que: «La venta colectiva de derechos de retransmisión es un buen ejemplo de solidaridad financiera y de mecanismo de redistribución en el deporte. Aunque en términos absolutos esta práctica restringe la competencia, tal como se entiende en el art. 101.1 TFUE, puede tener ventajas que compensen los efectos negativos. Por ello, en determinadas condiciones, la venta colectiva puede satisfacer los criterios que permiten hacer una excepción de conformidad con el art. 101.3 TFUE. La Comisión recomienda a las asociaciones deportivas establecer mecanismos de venta colectiva de derechos de retransmisión para garantizar una redistribución adecuada de los ingresos, dentro del estricto cumplimiento de la legislación de la UE sobre competencia y preservando el derecho del público a la información».

No se puede olvidar que en la actualidad los derechos audiovisuales de las competiciones deportivas son la fuente primordial de ingresos del deporte profesional, por lo que con la aprobación reciente del Real

tes, en 1999, el umbral de tolerancia se fija a un nivel tan bajo como para considerar que no tiene suficientemente en cuenta este fenómeno, deberá considerarse que dicha normativa no tiene justificación desde el objetivo que perseguía.

40 Además, los resultados de los estudios y experimentos efectuados tras la aprobación de la Decisión recurrida carecen, en todo caso, de relevancia para su examen de legalidad.

41 COM (2011) 12 final, punto 3.2, pág. 9. 
Decreto Ley 5/2015 para la comercialización de los derechos de explotación de contenidos audiovisuales de las competiciones de fútbol profesional, se da un paso de gigante en la estabilidad de los ingresos del fútbol profesional en España, y de un reparto claro de los derechos, a la vez que más equitativo que el existente hasta el momento con el necesario punto de solidaridad respecto al fútbol base.

Ninguna duda puede generar la regulación desde la aplicación de las reglas de competencia de la UE, puesto que con anterioridad ya se había optado por la venta conjunta de derechos en Alemania ${ }^{42}$, Inglaterra ${ }^{43} \mathrm{o}$ Italia $^{44}$. Lo importante desde las reglas de competencia de la UE es que exista una efectiva competencia en la comercialización de los derechos audiovisuales del fútbol, con un procedimiento de venta transparente y no discriminatorio, garantizando que un único comprador no pueda adquirir todos los derechos de televisión en directo, creando para ello distintos lotes de subasta, facilitando la accesibilidad al contenido para los operadores de televisión, radio y de los nuevos de medios de comunicación, y garantizando que todos los derechos se hallen disponibles en el mercado.

Desde tales premisas que se cumplen con la nueva normativa, la venta conjunta de derechos no puede tener sino ventajas para el conjunto de los actores del fútbol profesional, y para el interés general, en la medida que se garantice con los recursos obtenidos el cumplimiento de todas las obligaciones tributarias y fiscales del fútbol profesional.

Como colofón debe señalarse que el Tribunal de Justicia (TJ) avala frente a la FIFA y la UEFA las retransmisiones en abierto para acontecimientos de gran relevancia deportiva ${ }^{45}$. En tal sentido los Estados

42 Con Decisión de la Comisión, relativa a venta conjunta de derechos audiovisuales de la Bundesliga, de19 de enero de 2005, COMP/C-2/37.214.

43 Con Decisión de la Comisión, relativa a la venta conjunta de los derechos de difusión de la FA Premier League de 22 de marzo de 2006, COMP/38.173.

44 Con problemas recientes porque la Autoridad Antimonopolio de Italia (AGCM) ha multado el 20 de abril de 2016 a los canales televisivos de pago Mediaset Premium y Sky y a la Liga de Fútbol por un acuerdo que quebrantó la libre competencia en la licitación de derechos de emisión de partidos de la Serie A (Primera División) del trienio 2015-2018. La AGCM señala en un comunicado que la sanción asciende a 66 millones de euros, de los cuales 51.419.247 deberán ser abonados por Mediaset Premium, cuatro por Sky, 1.944.070 por la Liga de Fútbol italiana y 9.049.646 por la empresa de mercadotecnia Infront. Se alude a un «acuerdo restrictivo para la competencia» estipulado entre los sancionados para repartirse los derechos de emisión del fútbol en el trienio 2015-2018. La AGCM tilda de «incompatibles» los acuerdos «que puedan afectar al comercio entre los Estados miembros y que tengan por objeto impedir, restringir o falsear el juego de la competencia dentro del mercado interior» de conformidad con el art. 101 TFUE.

45 Las SSTJ de 17 de febrero de 2011, en los asuntos T- 385/07 y T- 68/08, y la STJ de 8 de marzo de 2011, en el asunto T-55/08, resuelven recursos interpuestos por la FIFA y la UEFA contra decisiones de la Comisión en el procedimiento previsto por el artículo 3 bis de la Directiva 89/552/CEE del Consejo, añadido por la Directiva 97/36/CE, relativas al ejercicio de actividades de radiodifusión televisiva, que permite a cada Estado miembro decidir acontecimientos deportivos de gran importancia para la sociedad, que deban emitirse en abierto. Al efecto, "el Estado miembro de que se trate establecerá una lista de acontecimientos, nacionales o no 
pueden fijar una lista de acontecimientos, nacionales o no nacionales, que consideren de interés general, y deben notificarlo inmediatamente a la Comisión, que en un plazo de tres meses verificará si dichas propuestas se ajustan al Derecho comunitario. Son precisamente estas últimas decisiones de la Comisión en relación con acontecimientos deportivos que deben transmitirse por televisión en abierto en Bélgica, Irlanda del Norte o Gran Bretaña, las recurridas ante el TJ por la FIFA y la UEFA, en la medida que son competiciones que ellas organizan, como son el campeonato mundial o la Eurocopa de fútbol.

El TJ rechaza en su totalidad los recursos. Por ejemplo, la FIFA niega la legalidad de la Decisión impugnada de la Comisión, por entenderla desproporcionada en la medida que se juzga de interés general todos los partidos del mundial de fútbol. «La FIFA imputa a la Comisión no haber especialmente motivado su conclusión de que la totalidad de los partidos de la Copa del Mundo, y no sólo los partidos "prime", deben considerarse como de gran importancia...». Se entendería como partidos "prime» los disputados por la selección nacional, las semifinales y la final. Sin embargo, el TJ responde que los partidos «no prime» determinan la suerte de las selecciones, y que todo el Mundial es un acontecimiento único.

Además el TJ razona que las alegaciones formuladas adolecen de confusión entre, por una parte, la gran importancia que reviste un acontecimiento para la sociedad - primer requisito que se debe cumplir y que constituye la razón imperiosa de interés general que justifica la restricción de una libertad fundamental garantizada por el Tratado- $y$, por otra parte, la proporcionalidad de la restricción en cuestión — segundo requisito que debe cumplir la normativa nacional que restrinja tal libertad.

A este respecto basta señalar que la Copa del Mundo puede ser considerada válidamente, en su conjunto, un acontecimiento de gran importancia para la sociedad, puesto que los índices de audiencia relativos a los partidos lo confirman. Por lo tanto, la imputación de que la lista controvertida sólo respondería a las exigencias de la proporcionalidad si comprendiera exclusivamente algunos partidos, por ser éstos los únicos que revisten gran importancia, parte de una premisa errónea. En tal sentido, a juicio del TJ, no se invalida la conclusión de la Comisión acerca del carácter proporcionado por la inclusión de la totalidad de los partidos de la Copa del Mundo en la lista de acontecimientos de interés general.

nacionales, que considere de gran importancia para la sociedad... Los Estados miembros notificarán inmediatamente a la Comisión cualesquiera medidas que tomen... En un plazo de tres meses a partir del momento en que se efectúe la notificación, la Comisión verificará si dichas medidas se ajustan al derecho comunitario y las comunicará a los demás Estados miembros... Publicará inmediatamente en el Diario Oficial... como mínimo una vez al año, la lista consolidada de las medidas tomadas por los Estados miembros». 